Welt gestärkt werden. Das Christentum ist vielleicht noch eine $\mathrm{Kraft}$, die es vermag, Staaten christlicher Tradition auch politisch zu verbinden. Asiens Freiheit wird sich jedoch nur auf kulturellen und religiösen Traditionen Asiens errichten lassen. Das Christentum ist in Ost- und Südostasien ein Fremdkörper, und die Politik des Westens sollte sich hüten, noch heute mit Vorstellungen, die dem missionarischen Denken verhaftet sind und damit aus historischer Zwangsläufigkeit mit dem Kolonialzeitalter verbunden werden, zu versuchen, die Völker Asiens zu gewinnen.

Dr. Bernhard Großmann, Hamburg

Frank N. Trager

Burma - From Kingdom to Républic. A Historical and Political Analysis.

Frederick A. Prager, Publisher. New York, Washington, London 1966. XIII, $455 \mathrm{~S}$.

Die Birmanische Union ist heute einer der verschlossensten Staaten der Welt außerhalb des Ostblocks. Nur wenigen Reisenden ist es möglich, ein auch nur kurzfristiges Aufenthaltsvisum für das Land $\mathrm{zu}$ erhalten, und Feldstudien für wissenschaftliche Untersuchungen im Landesinneren scheinen so gut wie ausgeschlossen zu sein.

Durch die Geschehnisse der letzten Jahre in Südostasien ist auch Birma trotz seiner isolationistischen Politik wieder interessant geworden. Jedes Einzelproblem Birmas jedoch, das man heute studieren will, wird von der Kenntnis der politischen Entwicklung bis in die jüngste Zeit ausgehen müssen, da die neuere Geschichte Birmas alle Lebensäußerungen des Landes ganz entscheidend beeinflußt hat. Das vorliegende Buch stellt diese Entwicklung dar, und sein Autor, der von 1951 bis 1953 Direktor des Punkt-IV-Programms in Birma war und das Land mehrfach bereist hat, versteht es in meisterhafter Weise, dem Leser ein abgerundetes Bild des gegenwärtigen Birma zu vermitteln, in dem Geschichte, Politik, Wirtschaft und Kultur untrennbar und sich gegenseitig erklärend miteinander verbunden werden.
In den ersten drei Kapiteln seines $\mathrm{Bu}$ ches beschreibt Trager die Geschichte der verschiedenen Dynastien Birmas in neuerer Zeit, das Vordringen der British East India Company, die englisch-birmanischen Kriege und die Verwaltung Birmas als Provinz Britisch-Indiens und ab 1937 als eigene britische Kolonie. Trager deckt schonungslos die imperialistische Politik Großbritanniens auf, die nur selten von Verständnis für Land und Volk Birmas getragen war. Dieses Verständnis war auch noch gering, als die im 4. Kapitel behandelte Unabhängigkeit errungen wurde. Man wußte in London nur wenig von der Unabhängigkeitsbewegung der Thakins, aus der alle späteren Führer Birmas erwuchsen - vor allem der uns aus Tragers Darstellung sehr plastisch entgegentretende, bereits 1947 ermordete Aung San.

In weiteren zwei Kapiteln werden die Unruhen geschildert, die das neue Staatswesen schon bald nach Erringung der Unabhängigkeit erschütterten, und hier hält Trager die merkwürdige Tatsache fest, daß Birma in seinem Kampfe gegen kommunistische Rebellen im Westen keine Unterstützung fand. Im Gegenteil genossen die aufständigen Karen die Sympathien des Westens, möglicherweise weil sie frühzeitig zum Christentum bekehrt worden waren, was sie nicht davon abhielt, zeitweilig mit den birmanischen Kommunisten gemeinsame Sache zu machen. Es liegt hier wieder einmal einer der Fälle vor, in denen westliche Politik sich von christlichen Überlegungen (ver-)leiten ließ, ohne zu beachten, daß gerade der Buddhismus eine der Kräfte in Birma war, auf deren Basis man schließlich einer Einigung des Landes näherkam.

In drei weiteren Kapiteln stellt Trager die Wirtschaftsplanung, die Regierungen $\mathrm{U} \mathrm{Nu}$ und die Regierungen $\mathrm{Ne}$ Win (1958-1960 und ab 1962) sowie in den restlichen sieben Kapiteln die Außenpolitik Birmas dar. Die Außenpolitik insbesondere war durch das mangelhafte Verständnis belastet, das der Westen und vor allem die USA Birma entgegenbrachten. Die problematischsten Fakten waren die mangelnde Energie 
auf Seiten der-USA bei der Evakuierung der von Yünnan aus auf birmanisches Territorium geflüchteten und von hier aus noch jahrelang mit nationalchinesischer und amerikanischer Unterstützung operierenden Kuomintang-Truppen sowie der Reisexport der USA, der diese nach Birma und Thailand zum drittgrößten Reisexporteur machte und die Absatzmärkte Birmas beeinträchtigte, dessen Exporte zum weitaus überwiegenden Teil aus Reis bestehen.

Birma war in den ersten Jahren nach der Erlangung der Unabhängigkeit bereit gewesen, einer größeren Allianz mit den Staaten des Westens beizutreten. Nachdem es hier jedoch auf eine durch seine Politik nicht $\mathrm{zu}$ rechtfertigende Zurückhaltung gestoßen war, entschied es sich in der Folge für eine strikte Neutralitätspolitik, die wiederum im Westen nur allzu of t mißverstanden wurde. Dabei spielte das besondere Verhältnis zur Volksrepublik China eine wesentliche Rolle, und man muß Trager dankbar sein dafür, daß er überzeugend nachweist, wie wenig Grund und Absicht Birma hat, sich dem mächtigen Nachbarn auszuliefern. Birma ist wie wenige der jungen Staaten geeignet zu studieren, was echte Neutralität heute bedeutet. Birmas Non-alignment ist bis in die neueste Zeit hinein echt geblieben, und es ist nicht bereit, sich die Wahl seiner außenpolitischen Partner von mächtigeren Staaten vorschreiben zu lassen.

Der junge Staat, der in seiner Geschichte oft genug bewiesen hat, daß er für seine Unabhängigkeit zu kämpfen bereit ist, begegnet noch immer nicht dem Vertrauen, das er verdient. Die Folge ist, $\mathrm{da} ß$ er sich in eine neue Isolierung begibt, die sicherlich nicht zu seinem Vorteil ausschlagen wird. Es wäre zu wünschen, daß das anregende Buch Tragers dazu beitragen könnte, die Mauer der Mißverständnisse und des Unwissens zu überwinden, die Birma leider auch heute noch von der westlichen Welt trennt.

Dr. Bernhard Großmann, Hamburg

\section{K. GANDHI}

Industrialize - and perish

Zusammengestellt von R. K. Prabhu. Veröffentlicht vom Navajivan Trust. Ahmedabad 1966, 120 S., Rs. 2.50

Dieses kleine Büchlein enthält ausschließlich kürzere und längere Auszüge aus Reden und Schriften Gandhis von 1915-1948 zur Frage, ob Indien die Lebensform der westlichen Industriegesellschaft übernehmen solle. Die durch den Titel bereits vorweggenommene Ablehnung dieser Frage ist indes nur zú verstehen, wenn die Grundhaltung der Lebensphilosophie Gandhis mitgedacht und gewürdigt wird. Die Weltanschauung Gandhis, innerhalb derer die hier behandelte Frage nur einen kleinen Ausschnitt darstellt, ist aber wiederum abhängig von der indischen Grundhaltung zur Existenz. Die indische Weltanschauung unterscheidet sich von dem modernen europäischen Weltbild grundsätzlich dadurch, daß sie ganz erheblich weiter reicht, und zwar räumlich und zeitlich. Räumlich erfaßt das indische Denken seit jeher den Menschen wesentlich von der Seele her und sieht das leibliche Leben nur als eine Erscheinungsform des Seelischen. Zeitlich erfaßt der Inder den Menschen in seinem psycho-somatischen Komplex nur als einen kleinen Ausschnitt innerhalb einer Kette von Existenzformen. Für die indische Weltanschauung mit ihrer moralisch ausgerichteten Psychologie einerseits und mit der Verantwortlichkeit der Wesen nicht nur für dieses Leben, sondern für alle seine früheren und späteren Existenzformen andererseits ist die westliche Auffassung des einmaligen und materiell definierten Lebens daher eine große Beschränktheit und Blindheit. Alle Argumente, die der Europäer etwa zugunsten der Industrialisierung vorbringen könnte, sind in den Wind gesprochen, solange man sich nicht über das Weltbild einig ist, innerhalb dessen eine Frage wie die Wirtschaftsstruktur behandelt werden soll. Über das vorliegende Büchlein mit Gandhis Warnungen vor einer Übernahme der europäischen Verstädterung, Industrialisierung und Massenproduk- 